\title{
Paisanos itinerantes: una hoja de ruta.
}

\author{
Geraldine Davies Lenoble \\ Universidad de Georgetown, Washington - Consejo Nacional de Investigaciones Científicas y \\ Técnicas, Universidad Nacional de Quilmes, Argentina \\ gsd5@georgetown.edu
}

Ensayo recibido: 06 de marzo de 2019. Aprobación final: 16 de julio de 2019.

\section{Resumen}

Ensayo analítico sobre el libro de Ricardo Salvatore (2018) Paisanos itinerantes. Orden estatal y experiencia subalterna en Buenos Aires durante la era de Rosas. Buenos Aires: Prometeo. Se realiza un análisis integral de la obra en su nueva edición en español, y se reflexiona sobre sus aportes en la comprensión del impacto del orden rosista en la historia Argentina del siglo XIX.

Palabras clave: Rosas; sectores subalternos; trabajadores rurales.

\section{Paisanos Itinerantes: a Roadmap}

\begin{abstract}
Analytical essay on Ricardo Salvatore (2018). Paisanos itinerantes. Orden estatal y experiencia subalterna en Buenos Aires durante la era de Rosas. Buenos Aires: Prometeo. It presents a comprehensive analysis of the new Spanish edition of the book; it also ponders Salvatore's contribution to our understanding of the impact of Rosas' regime in the Argentine History of the 19th century.
\end{abstract}

Keywords: Rosas; subaltern sectors; rural workers.

1 Comentarios revisados de la presentación sobre Paisanos itinerantes... realizada en la Universidad Torcuato Di Tella, 17 de octubre del 2018. 
En esta hoja de ruta presentaré las particularidades de esta nueva edición de Wandering Paisanos, de Ricardo Salvatore, su análisis y argumentos principales, y realizaré algunos comentarios que apuntan a reflexionar sobre las continuidades y rupturas que presentó el orden rosista en la historia Argentina del siglo XIX.

El autor decidió traducir la mayor parte de su obra sin modificaciones, elección que creo acertada principalmente porque su versión en inglés es una de las referencias más importantes sobre el período rosista, y contiene una complejidad analítica y metodológica que sigue resultando relevante a los debates actuales. A su vez, Salvatore no deja de indicar por dónde continuaron sus interrogantes. Por un lado, finaliza esta nueva edición con una respuesta a doce reseñas que se han realizado sobre su libro. Éstas destacan y discuten las contribuciones metodológicas y argumentativas más importantes de la obra, y sugieren futuros trabajos comparativos con otros casos de caudillismo de América Latina que se centren en la relación estado-campesinos. Por otro lado, en su prólogo, el autor promete publicar una secuela de Paisanos Itinerantes..., en donde estudiará a otros sectores subalternos, como morenos, mujeres pobres e indígenas. Esta nueva investigación no sólo le permitirá analizar otros parámetros de subalternidad, como el género y la etnicidad, sino también dialogar con campos historiográficos que han crecido considerablemente en las últimas décadas, como la historia indígena y de frontera.

Salvatore presenta un complejo marco analítico, conceptual e historiográfico que guía sus indagaciones a lo largo de la obra. La principal influencia metodológica proviene de los estudios subalternistas, el grupo de investigaciones surgido en la India en la década de 1980 que renovó la historia cultural y social, incorporando a los sectores sublaternos, problematizando el uso de los archivos y las perspectivas de poder. Si bien el autor explica las principales diferencias del caso indio y el de la Argentina rosista, encuentra en estos estudios una importante herramienta metodológica para comprender la experiencia subalterna. Su método consiste en reconstruir tanto el discurso dominante del orden rosista y sus instituciones disciplinarias, como las experiencias de desafío y resistencia de los sectores menos favorecidos por el régimen, especialmente los peones y campesinos. Con este doble objetivo, utiliza y analiza una gran variedad de fuentes judiciales, militares, correspondencia oficial, poesía y narrativas políticas.

¿Por qué se centra en los peones y campesinos? Salvatore explica que, en el contexto de la post-independencia, en donde las guerras civiles y la expansión ganadera demandaban gran cantidad de peones-soldados, el orden rosista intentó controlar y disciplinar a los pobres rurales. Incluso, creó una categoría especial para agruparlos y controlarlos: la "clase del peón de campo". Desde esta observación proviene el foco y título de esta obra. El autor revierte el mecanismo disciplinario del rosismo y recategoriza a los pobres rurales desde sus voces de resistencia. Indica que estos sectores no se percibían como clase social o comunidad colectiva; por el contrario,en sus testimonios solían remarcar su individualidad e identificarse más frecuentemente como "paisanos". Esta categoría indicaba la pertenencia a una comunidad rural o pueblo, pero no refería a una condición de inferioridad social. A su vez, el aspecto compartido por todos estos actores era su movilidad espacial y ocupacional, de ahí la itinerancia. 
Desde un doble foco analítico, Paisanos itinerantes desafía tres interpretaciones tradicionales del rosismo: la que presenta al régimen como un reproductor del feudalismo ganadero y el peonaje dependiente; la que ve a Juan Manuel de Rosas como un representante y gobernante de la clase terrateniente bonaerense; y, por último, la que entiende la relación entre Rosas y las clases bajas como un vínculo paternal de seducción y castigo. Pero Salvatore no reemplaza estas interpretaciones por otra igualmente estática y totalizante; su alternativa consiste en develar las múltiples tensiones y lugares de conflicto. Creo que aquí radica gran parte de la complejidad interpretativa de este trabajo, y la vigencia de sus observaciones quince años después de su primera publicación.

A lo largo de doce capítulos temáticos, la obra trata cuatro campos de poder del orden rosista: el mercado, la justicia, el ámbito militar y la política. En los primeros tres capítulos muestra cómo la escasez de mano de obra y la expansión del mercado le permitieron a los pobres rurales mayores niveles de negociación. En vez de relaciones paternalistas entre ganaderos y paisanos, encuentra actores subalternos que operaban bajo una suerte de "liberalismo popular", ya que buscaban contratos temporales y resistían todo tipo de regulaciones para conservar su movilidad. Sin embargo, también devela que otros actores, como las mujeres de los soldados, reclamaban derechos de asistencia a una especie de "proto-estado de bienestar". Además de marcar estas tendencias contradictorias, agrega que la asistencia estatal habría impactado positivamente en el bienestar nutricional de los sectores subalternos. Esta observación destaca un importante mecanismo de medición que desafía el uso exclusivo de indicadores económicos tradicionales, como el salario real, para dar cuenta del bienestar de las clases pobres. En trabajos posteriores, Salvatore continuó estudiando los cambios en el bienestar nutricional de la población argentina del siglo XX (Salvatore, 2010).

Entre el capítulo octavo y décimo, Salvatore analiza el ámbito militar como una institución de disciplinamiento social, develando la gran influencia que también ha tenido Michel Foucault en sus investigaciones. Sin embargo, argumenta que en lugar de "escuelas de disciplina social", las guarniciones militares habrían funcionado como "niveladores sociales", al mezclar delincuentes convictos y vecinos-ciudadanos, y "escuelas de protesta”. Allí se negociaban los términos de contratación, se exigían beneficios y la deserción funcionaba como un arma de negociación; se generaba también una "opinión pública popular" que amenazaba la estabilidad del régimen. El autor se pregunta si no fueron los mismos soldados los que comenzaron a mostrar un revés político y no defendieron a Rosas en Caseros. Este análisis evidenciaría la agencia de los subalternos en la política y la formación del estado. A su vez, muestra el importante rol que el aparato militar seguía cumpliendo en la política argentina como espacio de negociación entre subalternos y elites, y la continuidad de una práctica política caracterizada por el "ciudadano en armas". Los trabajos que se han realizado sobre las guerras civiles post-rosistas y las montoneras federales, mostrarían la continuidad de estas tendencias (ver Bragoni y Míguez, 2010).

En contraste con la ambigüedad encontrada en el ámbito militar, Paisanos itinerantes devela un mayor nivel de coacción estatal y menor capacidad de maniobra del 
subalterno en el ámbito de la justicia, tratada principalmente entre los capítulos quinto y séptimo. Salvatore demuestra la importancia que el régimen le otorgó a la ley como "retórica oficial, pedagogía de costumbres, y realidad del poder" (p. 242). En este espacio, se perciben con claridad las ambigüedades del régimen. Mientras que éste acercaba al subalterno al marco de la ley, también lo reprimía. Por ejemplo, se celebraba la vestimenta del hombre de campo frente al unitario de levita, pero se criminalizaba ese mismo aspecto a la hora de controlar a los paisanos itinerantes. Teniendo en cuenta los trabajos posteriores realizados por el autor sobre la justicia de estado y los sectores subalternos (Salvatore, Aguirre y Joseph, 2001), la justicia rosista parece haber marcado un cambio significativo respecto a los periodos anteriores, dejando a los gobiernos liberales que le precedieron -especialmente entre 1852 y 1880 - una importante institución de disciplinamiento y control. Pero aquí nos preguntamos si la justicia tuvo el mismo desarrollo fuera de la provincia de Buenos Aires, en donde los aparatos burocráticos escaseaban de recursos y la política facciosa generó largas décadas de inestabilidad. Allí el control real de las elites políticas se limitaba a los centros urbanos de sus provincias y su expansión dependía de redes de recursos y lealtades establecidas con líderes territoriales (Bragoni y Míguez, 2010).

Por último, la obra analizada también estudia las tensiones y ambigüedades del rosismo en el ámbito político, tema tratado más explícitamente en los capítulos sobre los recuerdos de guerra (capítulo 10) y las fiestas federales (capítulo 11). El autor adhiere a la interpretación de Jorge Myers sobre el discurso político rosista como promotor de un "republicanismo popular" que establecía una suerte de pacto entre el estado y los paisanos. Mientras que los últimos formaban y defendían la federación (entendida como una comunidad imaginada), el estado les proveía "de tierras, raciones para sus familias y derechos políticos" (Myers, 1995). Sin embargo, Salvatore señala que este pacto también se caracterizó por una dura coacción, y que era en esa tensión en donde se producía la resistencia. En palabras del autor: "Los paisanos sin tierra vestidos ahora con uniformes militares eran forzados a servir a la nación de una forma que contradecía las promesas de igualdad y libertad que la República les había hecho. Toleraban los festivales patrióticos protegiendo desde afuera la alegría de otros, esperando la primera oportunidad para desertar" (p. 470). Como resultado de esta tensión, los subalternos habrían contribuido a construir el orden establecido a través de sus demandas de derechos de residencia, empleo, libertad, alimentación, entre otros. Aquí nos preguntamos por la relación de este análisis y la obra de Ariel de la Fuente sobre el federalismo popular en los Llanos de la Rioja (De la Fuente, 2007). Ambos trabajos parecen argumentar a favor de la existencia de un proyecto federal y republicano fuertemente enraizado y defendido por los sectores populares, que dialogaría con las elites federales y unitarias. Sin embargo, en el caso de Buenos Aires parece un fenómeno más fragmentado y disperso, que aparece en los testimonios de los subalternos, pero no se trasforma en "un movimiento" como las montoneras federales de los Llanos. Tampoco se ha argumentado por la existencia de fuertes componentes étnicos en aquellas demandas y resistencia, como sí se ha hecho en la región de Cuyo y el norte argentino. ${ }^{2}$ Quedaría entonces 
por explorar si esta particularidad responde a una cuestión de interpretación o a contextos estructurales y políticos diferentes. Resultaría clave extender el estudio del mercado, la justicia y el aparato militar a las provincias de Cuyo y el norte, así como incorporar el estudio de la etnicidad en el caso bonaerense.

En el último capítulo, Salvatore retoma las discusiones historiográficas sobre el régimen rosista y explica cómo este pacto entre el estado y los pobres rurales habría terminado con la caída de Rosas en Caseros y la emergencia de la elite liberal, cuyo foco giró hacia otros subalternos (inmigrantes, mujeres y pueblos originarios). Los paisanos itinerantes se invisibilizaron en las fuentes. Sin embargo, los estudios realizados sobre el mundo rural post-rosista probablemente encuentren importantes continuidades. Si Wandering Paysanos fue un importante punto de partida para comprender el rosismo y su legado, Paisanos itinerantes resulta un gran estímulo para extender este tipo de análisis a otras provincias y períodos de la historia argentina. Por último, quiero destacar el impresionante trabajo de traducción; el libro se lee casi en su totalidad como si se hubiera escrito en español. Valió la pena la espera. 


\section{Bibliografía}

" Bragoni, B. y Míguez, E. (Coords.) (2010). Un nuevo orden político: provincias y estado nacional, 1852-1880. Buenos Aires: Biblos.

"De la Fuente, A. (2007). Los hijos de Facundo: caudillos y montoneras en la provincia de La Rioja durante el proceso de formación del Estado Nacional Argentino (1853-1870). Buenos Aires: Prometeo.

"Escolar, D. (2007). Los dones étnicos de la Nación: Identidades Huarpe y modos de producción de soberanía en Argentina. Buenos Aires: Prometeo.

" Myers, J. (1995). Orden y virtud: el discurso republicano en el régimen rosista. Buenos Aires: Universidad Nacional de Quilmes.

"Salvatore, R. (2010). Better-Off in the Thirties: Welfare Indices for Argentina, 1900-1940. En R. Salvatore, J. Coatsworth y A. Challú (eds.), Living Standars in Latin American History. Cambridge: Harvard University Press, pp. 127-165.

" Salvatore, R., Aguirre, C. y Gilbert M. Joseph (eds.) (2001). Crime and Punishment in Latin America: Law and Society since Late Colonial Times. Durham: Duke University Press; , y Salvatore, R. (2013). Subalternos, derechos y justicia penal: ensayos de historia social y cultural argentina 1829-1940. Buenos Aires: Gedisa. 